Tropical Journal of Pharmaceutical Research September 2017; 16 (9): 2161-2168

ISSN: 1596-5996 (print); 1596-9827 (electronic)

(C) Pharmacotherapy Group, Faculty of Pharmacy, University of Benin, Benin City, 300001 Nigeria.

All rights reserved.

Available online at http://www.tjpr.org

Original Research Article

http://dx.doi.org/10.4314/tjpr.v16i9.17

\title{
Curative role of lactulose, L-carnitine, alpha-lipoic acid and combination of L-carnitine and alpha-lipoic acid in a rat model of acute hepatic encephalopathy: Biochemical observations
}

\author{
Rokaya Mohamed Aly Saeed', Hanaa Hamdy Ahmed ${ }^{2}$, Afaf Abbass Sayed \\ Saleh $^{1 *}$ and Yassmen Said Ahmed ${ }^{1}$
}

${ }^{1}$ Department of Zoology, Faculty of Women for Arts, Science and Education, Ain Shams University, ${ }^{2}$ Hormones Department, Medical Research Division, National Research Centre, Dokki, Cairo, Egypt

*For correspondence: Email: afafabas1@yahoo.com; Tel: +2 01111757602

Sent for review: 9 March 2017

Revised accepted: 13 August 2017

\begin{abstract}
Purpose: To determine whether a combination L-carnitine and $\alpha$-lipoic acid (ALA) can alleviate the toxic effects of thioacetamide (TAA) via their potent antioxidant and free radical-scavenging activities.

Methods: Rats were injected with TAA for 3 days to induce acute hepatic failure. TAA induced rats were treated with each of lactulose, L-carnitine and ALA alone and a combination of L-carnitine and ALA for 3 months. Thereafter, biochemical indices, ammonia levels, oxidative stress markers, and the levels of inflammatory markers were assessed in serum, liver and brain.

Results: A significant improvement was observed after 3 months of antioxidants treatment. Lactulose, L-carnitine and ALA significantly decreased serum concentrations of alanine transaminase (ALT), aspartate aminotransaminase (AST) and level of total bilirubin while both levels of total protein (TP) and albumin $(A L B)$ were significantly increased $(p<0.05)$ compared to TAA group. In addition, each of antioxidants alone significantly decreased ammonia (NH3) concentrations of serum, liver and brain in TAA-induced rats. Treatment with antioxidants for 3 months significantly $(p<0.05)$ decreased Malondialdehyde (MDA) and nitric oxide (NO) while antioxidant enzyme activities of glutathione peroxidase (GPX) and superoxide dismutase $(S O D)$ were significantly increased $(p<0.05)$ in liver and brain tissues. The expressions of serum tumor necrosis factor- $\alpha$ (TNF- $\alpha$ ) and soluble protein (S100- $\beta$ ) were significantly $(p<0.05)$ down-regulated in TAA-induced rats.

Conclusion: L-carnitine in combination with ALA can mitigate HE induced experimentally in rats. The protective efficacy of L-carnitine in combination with ALA in HE can be attributed to suppression of oxidative stress, ammonia concentration and the levels of inflammatory markers. Thus, it may have the potential to be used to treat liver cirrhosis in clinical settings.
\end{abstract}

Keywords: Lactulose, L-carnitine, a-Lipoic acid, Hepatic encephalopathy, Thioacetamide, Oxidative stress, Cirrhosis, Acute liver injury

Tropical Journal of Pharmaceutical Research is indexed by Science Citation Index (SciSearch), Scopus, International Pharmaceutical Abstract, Chemical Abstracts, Embase, Index Copernicus, EBSCO, African Index Medicus, JournalSeek, Journal Citation Reports/Science Edition, Directory of Open Access Journals (DOAJ), African Journal Online, Bioline International, Open-J-Gate and Pharmacy Abstracts

\section{INTRODUCTION}

$\mathrm{HE}$ is a neuropsychiatric syndrome that occurs in both cirrhosis and acute liver failure (ALF). HE is a significant cause of morbidity and mortality in advanced cirrhotic patients. Affected patients exhibit alterations in psychomotor, intellectual, cognitive, emotional and behavioral. In addition to, hyperammonemia is responsible for both direct and indirect alterations in cerebral 
metabolism in HE [1]. TAA is a thiocarbonyl compound which has been used as a fungicide, organic solvent, and stabilizer of motor oil. TAAinduced acute liver failure is used as acute liver injury model and it has been widely studied in rats and in other animal species using different doses, times and routes of administration. Moreover, biochemical and histological changes observed in human cirrhosis are similar to those observed in experimental TAA-induced liver cirrhosis [2].

There are a few therapeutic strategies, and outcome expectations for patients with HE. Lactulose is a synthetic, non-digestible sugar used in the treatment of chronic constipation and HE. It is a disaccharide formed from monosaccharide (fructose and galactose) and it is produced commercially by isomerization of lactose. Lactulose has been shown to improve quality of life and cognitive function in patients with cirrhosis and minimal hepatic encephalopathy. Moreover, lactulose therapy can improve blood ammonia and reduce the risk of developing overt encephalopathy. Recently, it remains the mainstay therapy for $\mathrm{HE}$ [3].

L-carnitine and its acyl- derivatives are as potential antioxidants and low-cost therapeutic agents [4]. In animal models, L-carnitine has been shown to counteract neurotoxic effects of ammonia, improve energy metabolism and greater improvements in neuropsychological functioning [5]. Furthermore, L-carnitine supplementation has hepatoprotective effect, maintained and improved liver function as well as patients with liver cirrhosis (LC) [6].

ALA and its reduced form dihydrolipoic acid (DHLA), are natural compounds widely distributed in plants and animals. They are synthesized through a reaction catalyzed by lipoic acid sysnthase within the mitochondria of the liver, heart and kidney. ALA Possesses a unique antioxidant ALA/DHLA system. Thus, DHLA is able to reduce not only reactive oxygen species (ROS) but also oxidize forms of other antioxidants [7]. Due to thiol groups and free thiols, ALA is essential in GSH synthesis, thereby maintaining maximum levels of other antioxidants such as vitamins $C$ and $E, S O D$ and catalase (CAT) [8]. ALA also easily penetrates all cells and tissues of the body, including the blood brain barrier (BBB) and increases the synthesis of acetylcholine and thereby maintains the integrity of the brain [9].

Accordingly, this study aims to explore the protective efficacy of Lactulose, L-carnitine and
ALA treatment and the combination L-carnitine and ALA against TAA - induced HE in rats.

\section{EXPERIMENTAL}

\section{Experimental animals}

The protocol for the present study was approved by the Research Ethics Committee at the Faculty of Science - Ain Shams University, Egypt (REC - FS ref. no. 00032).

Eighty adult male albino rats weighing 120 - 150 $\mathrm{g}$ were obtained from the Animal House Colony of the National Research Centre, Cairo, Egypt and allowed to acclimate to the animal facility for one week prior to the experiment. The rats were housed at $25 \pm 2{ }^{\circ} \mathrm{C}$ with a 12-h light-dark cycle.

The animals received a standard pellet diet and tap water ad libitum compliance with the guidelines of the National Research Council (NRC) [10].

\section{Induction of acute liver injury to rats}

TAA is extensively used as a model of acute hepatic failure. TAA dissolved in physiological saline and induced fulminant hepatic failure through three consecutive i.p injections of TAA (100 $\mathrm{mg} / \mathrm{kg}$ i.p) to rats daily for 3 consecutive days.

\section{Drugs and doses}

In the current study, the pharmacological doses of lactulose, L- carnitine and ALA were applied (8 $\mathrm{mg} / \mathrm{kg} /$ day, $\quad 100 \mathrm{mg} / \mathrm{kg} /$ day and $100 \mathrm{mg} / \mathrm{kg} /$ day, respectively). Lactulose, Lcarnitine and ALA were prepared in sterile distilled water and administered orally.

TAA was purchased from Sigma Chem. Co. (St. Louis, Mo, USA). Lactulose, L-carnitine and ALA were purchased from EVA PHARMA Egypt. Each $100 \mathrm{ml}$ of Lactulose contain $65 \mathrm{mg}$ of Lactulose. Each capsules of L-carnitine contains $350 \mathrm{mg}$ of L-carnitine while each capsules of ALA contains $600 \mathrm{mg}$ of ALA.

\section{Experimental design and protocol}

After one week acclimatization, eight groups were formed $(n=10)$ and treated as follows:

Group (1): rats injected daily $1 \mathrm{~mL}$ physiological saline i.p for 3 days (control group 3 days). Group (2): rats received TAA (100 $\mathrm{mg} / \mathrm{kg}$ i.p) for 3 consecutive days (TAA 3 days). Group (3): rats injected daily $1 \mathrm{ml}$ physiological saline i.p for 3 
days and left untreated for 3 months (control group 3 months). Group (4): rats administered TAA (100 mg/ kg i.p) daily for 3 consecutive days and left untreated for 3 months (TAA 3 months). Group (5): rats received TAA (100 mg/kg i.p) daily for 3 consecutive days and then treated with lactulose $(8 \mathrm{ml} / \mathrm{kg}$. orally) daily for 3 months (TAA+ lactulose). Group (6): rats received TAA (100 mg/kg. i.p) daily for 3 consecutive days and then treated with L-carnitine (100 $\mathrm{mg} / \mathrm{kg}$ orally) daily for 3 months (TAA+ L-carnitine). Group (7): rats injected TAA (100 $\mathrm{mg} / \mathrm{kg}$ i.p) daily for 3 consecutive days and then treated with ALA (100 $\mathrm{mg} / \mathrm{kg}$ orally) daily for 3 months (TAA+ a-lipoic acid). Group (8): rats received TAA (100 mg/kg i.p) daily for 3 consecutive days and then treated with a combined dose of both L-carnitine and ALA daily for 3 months (TAA+ L-carnitine+ $\alpha$ lipoic acid).

At the end of the experimental period, the animals were fasted for $12 \mathrm{~h}$, and blood samples were collected from the retro-orbital venous plexus in clean dry test tubes under diethyl ether anesthesia. The blood samples were centrifuged at $1800 \mathrm{xg}$ for $15 \mathrm{~min}$ at $4{ }^{\circ} \mathrm{C}$. Sera were separated and stored at $20{ }^{\circ} \mathrm{C}$ for biochemical analyses.

\section{Preparation of liver and brain homogenates}

After blood collection, all animals were sacrificed by decapitation and the whole liver and brain of each animal were rapidly excised, thoroughly washed with isotonic saline and blotted dry. Subsequently, the liver and brain were weighed and a portion of each tissue was homogenized. Liver was immediately homogenized in $50 \mathrm{mM}$ ice-cold phosphate buffer ( $\mathrm{pH} 7.4)$ to give 20 $\% w / v$ homogenate according to Lin et al [11]. The brain was immediately homogenized to give $10 \% \mathrm{w} / \mathrm{v}$ homogenate in an ice-cold medium containing $50 \mathrm{mM}$ Tris- $\mathrm{Hcl}$ and $300 \mathrm{mM}$ sucrose, $\mathrm{pH} 7.4$ as described by Tsakiris [12]. The homogenates were centrifuged at $1800 \mathrm{xg}$ for 10 $\min$ in refrigerated centrifuge at $4{ }^{\circ} \mathrm{C}$. The supernatants of the liver and brain tissue homogenate were separated for biochemical analyses.

\section{Determination of serum ALT, AST, TP, ALB and bilirubin}

The activities of serum ALT and AST were determined spectrophotometrically using an automated analyzer method (Opera Technician Bayer Auto analyzer). Serum total protein (TP) level was determined by colorimetric point method. Serum albumin (ALB) level was determined by quantitative colorimetric method.
Serum total bilirubin level was determined by colorimetric method.

\section{Assessment of serum, liver and brain ammonia level}

Ammonia $\left(\mathrm{NH}_{3}\right)$ level was measured using standard kits, based on the absorbance photometry method of phenate-hypochlorate reaction.

\section{Evaluation of MDA and NO levels}

Malondialdehyde (MDA) levels were assayed by monitoring thiobarbituric acid reactive substance formation. The principle of the method is the spectrophotometric measurement of the color generated by the reaction of thiobarbituric acid substance (TBA) with MDA. Lipid peroxidation was expressed in terms of MDA equivalents using an extinction coefficient of $1.56 \times 105 \mathrm{M}^{-1}$ $\mathrm{cm}^{-1}$ and the levels of MDA were expressed as $\mathrm{nmol} \mathrm{MDA} / \mathrm{g}$ tissue. The commercial ELISA kit of MDA and nitric oxide (NO) were purchased from Oxford Biomedical Research Inc., USA.

\section{Determination of GPX and SOD activities}

The activities of Glutathione peroxidase (GPX) and superoxide dismutase (SOD) were measured by ELISA technique using commercial kits (Gesellschaft, Hamburg Germany).

\section{Analysis of serum $\alpha-T N F-\alpha$ and S100- $\beta$ level}

Serum tumor necrosis factor- $\alpha$ (TNF- $\alpha$ ) level was assayed by ELIZA technique using TNF- $\alpha$ assay kit purchased from Glory Science Co., Ltd, TX, USA and quantitative determination of serum soluble protein S100- $\beta$ ) was carried out using S100- $\beta$ ELIZA assay kit purchased from ELHAB Co. (China).

\section{Statistical analysis}

Data are expressed as mean \pm SE and were evaluated by one-way analysis of variance (ANOVA) followed by least significant difference (LSD) test using SPSS, version 10 software. $P<$ 0.05 was considered to be significant difference between treatments.

\section{RESULTS}

Administration of TAA (100 mg/kg, i.p) showed significant elevation in serum marker enzyme activities (ALT and AST) and serum bilirubin level with significant decline in serum TP and ALB levels (Table 1). 
Table 1: Effect of lactulose, L-carnitine, ALA and the combined dose of L-carnitine and ALA on serum liver function tests in TAA-induced HE in rats

\begin{tabular}{lccccc}
\hline Group & $\begin{array}{c}\text { ALT } \\
(\mathbf{U} / \mathbf{L})\end{array}$ & $\begin{array}{c}\text { AST } \\
(\mathbf{U} / \mathbf{L})\end{array}$ & $\begin{array}{c}\text { TP } \\
(\mathbf{g} / \mathbf{d L})\end{array}$ & $\begin{array}{c}\text { ALB } \\
(\mathbf{g} / \mathbf{d L})\end{array}$ & $\begin{array}{c}\text { Bilirubin } \\
(\mathbf{m g} / \mathbf{d L})\end{array}$ \\
\hline Normal control (3 days) & $30.07 \pm 0.50$ & $55.0 \pm 0.63$ & $7.77 \pm 0.02$ & $4.11 \pm 0.03$ & $0.923 \pm 0.04$ \\
TAA (3 days) & $177.97 \pm 2.63^{\mathrm{a}}$ & $186.14 \pm 2.03^{\mathrm{a}}$ & $4.80 \pm 0.03^{\mathrm{a}}$ & $2.17 \pm 0.01^{\mathrm{a}}$ & $2.28 \pm 0.06^{\mathrm{a}}$ \\
Normal control (3 months) & $29.71 \pm 0.42$ & $54.50 \pm 0.57$ & $7.80 \pm 0.02$ & $4.11 \pm 0.02$ & $1.00 \pm 0.05$ \\
TAA (3 months) & $321.0 \pm 5.18^{\mathrm{b}}$ & $342.45 \pm 3.83^{\mathrm{b}}$ & $4.21 \pm 0.03^{\mathrm{b}}$ & $1.89 \pm 0.03^{\mathrm{b}}$ & $3.54 \pm 0.06^{\mathrm{b}}$ \\
TAA + Lactulose & $139.75 \pm 1.38^{\mathrm{c}}$ & $125.57 \pm 2.13^{\mathrm{c}}$ & $6.03 \pm 0.05^{\mathrm{c}}$ & $3.50 \pm 0.02^{\mathrm{c}}$ & $1.70 \pm 0.01^{\mathrm{c}}$ \\
TAA + L-carnitine & $170.0 \pm 2.20^{\text {ca }}$ & $166.42 \pm 2.90^{\text {ca }}$ & $5.67 \pm 0.05^{\mathrm{cd}}$ & $2.89 \pm 0.21^{\mathrm{cd}}$ & $2.20 \pm 0.01^{\mathrm{cd}}$ \\
TAA + ALA & $187.86 \pm 2.58^{\text {cde }}$ & $196.58 \pm 2.91^{\text {cde }}$ & $5.54 \pm 0.04^{\text {cde }}$ & $2.50 \pm 0.02^{\text {cde }}$ & $2.40 \pm 0.02^{\text {cde }}$ \\
TAA + L-carnitine + ALA & $156.43 \pm 1.86^{\text {cdet }}$ & $153.85 \pm 2.87^{\text {cdet }}$ & $5.81 \pm 0.04^{\text {cdet }}$ & $3.00 \pm 0.03^{\text {cdet }}$ & $1.90 \pm 0.01^{\text {cdet }}$ \\
\hline
\end{tabular}

Values represent mean \pm SE, number of samples is 10 rats per group; $a ; b ; c ; d ;$; $f$ Significant at $p<0.05$ between the groups in the same rows

Lactulose, L-carnitine and ALA (8 $\mathrm{mg} / \mathrm{kg} /$ day, $100 \mathrm{mg} / \mathrm{kg} / \mathrm{day}$ and $100 \mathrm{mg} / \mathrm{kg} / \mathrm{day}$, respectively) treatment of $\mathrm{HE}$ - induced rats resulted in a significant improvement in the levels of these parameters compared to the HE group. The ammonia concentrations was significantly higher $(p<0.05)$ in the serum, liver and brain of HE group compared to control rats whereas it was significantly lower in Lactulose, L-carnitine and ALA groups (Table 2).
The liver and brain MDA and NO levels were significantly increased $(p<0.05)$ in the HE group than in the control whereas GPX and SOD activities were significantly lower $(p<0.05)$. Lactulose, L-carnitine and ALA treatment rats showed that MDA and NO levels significantly declined $(p<0.05)$ whereas GPX and SOD activities were significantly increased (Table 3, Table 4).

Table 2: Effect of lactulose, L-carnitine, ALA and the combined dose of L-carnitine and ALA on serum, liver and brain ammonia levels in TAA-induced HE in rats

\begin{tabular}{lccc}
\hline Group & $\begin{array}{c}\text { Serum ammonia } \\
(\mu \mathrm{mol} / \mathrm{mL})\end{array}$ & $\begin{array}{c}\text { Liver ammonia } \\
(\mu \mathrm{mol} / \mathrm{g} \text { wet tissue) }\end{array}$ & $\begin{array}{c}\text { Brain ammonia } \\
(\mu \mathrm{mol} / \mathrm{g} \text { wet tissue) }\end{array}$ \\
\hline Normal control (3 days) & $0.21 \pm 0.002$ & $0.60 \pm 0.01$ & $0.33 \pm 0.01$ \\
TAA (3 days) & $1.02 \pm 0.014^{\mathrm{a}}$ & $2.44 \pm 0.040^{\mathrm{a}}$ & $0.62 \pm 0.01^{\mathrm{a}}$ \\
Normal control (3 months) & $0.21 \pm 0.003$ & $0.60 \pm 0.01$ & $0.33 \pm 0.01$ \\
TAA (3 months) & $1.48 \pm 0.003^{\mathrm{b}}$ & $3.88 \pm 0.10^{\mathrm{b}}$ & $1.12 \pm 0.02^{\mathrm{b}}$ \\
TAA + Lactulose & $0.63 \pm 0.008^{\mathrm{c}}$ & $1.65 \pm 0.03^{\mathrm{c}}$ & $0.64 \pm 0.02^{\mathrm{c}}$ \\
TAA + L-carnitine & $0.93 \pm 0.012^{\mathrm{cd}}$ & $1.95 \pm 0.02^{\mathrm{cd}}$ & $0.97 \pm 0.003^{\mathrm{cd}}$ \\
TAA + ALA & $1.07 \pm 0.04^{\text {cde }}$ & $2.10 \pm 0.03^{\text {cde }}$ & $0.99 \pm 0.01^{\mathrm{cd}}$ \\
TAA + L-carnitine + ALA & $0.75 \pm 0.007^{\text {cdet }}$ & $1.85 \pm 0.03^{\text {cat }}$ & $0.82 \pm 0.02^{\text {cdet }}$ \\
\hline
\end{tabular}

Values represent mean \pm SE, number of samples is 10 rats per group; $a ; b ; c ; d ; e ; f$ Significant at $p<$ 0.05 between the groups in the same rows

Table 3: Effect of lactulose, L-carnitine, ALA and the combined dose of L-carnitine and ALA on liver oxidant/antioxidant homeostasis in TAA-induced HE in rats

\begin{tabular}{lcccc}
\hline Group & $\begin{array}{c}\text { MDA } \\
(\mathbf{n m o l} / \mathbf{m g} \text { protein) }\end{array}$ & $\begin{array}{c}\text { NO } \\
(\boldsymbol{\mu} \text { mol/mg protein) }\end{array}$ & $\begin{array}{c}\text { GPX } \\
(\mathbf{U} / \mathbf{m g} \text { protein) }\end{array}$ & $\begin{array}{c}\text { SOD } \\
(\mathbf{U} / \mathbf{m g} \text { protein })\end{array}$ \\
\hline Normal control (3 days) & $17.79 \pm 0.15$ & $5.58 \pm 0.11$ & $1.15 \pm 0.01$ & $99.70 \pm 0.96$ \\
TAA (3 days) & $34.82 \pm 0.39^{\mathrm{a}}$ & $13.47 \pm 0.05^{\mathrm{a}}$ & $0.81 \pm 0.01^{\mathrm{a}}$ & $81.70 \pm 0.73^{\mathrm{a}}$ \\
Normal control (3 months) & $17.96 \pm 0.09$ & $5.46 \pm 0.08$ & $1.15 \pm 0.01$ & $98.82 \pm 1.00$ \\
TAA (3 months) & $52.22 \pm 0.64^{\mathrm{b}}$ & $21.08 \pm 0.19^{\mathrm{b}}$ & $0.65 \pm 0.01^{\mathrm{b}}$ & $69.26 \pm 0.50^{\mathrm{b}}$ \\
TAA + Lactulose & $25.00 \pm 0.34^{\mathrm{c}}$ & $13.64 \pm 0.21^{\mathrm{c}}$ & $0.98 \pm 0.07^{\mathrm{c}}$ & $88.00 \pm 0.07^{\mathrm{c}}$ \\
TAA + L-carnitine & $29.99 \pm 0.34^{\text {cd }}$ & $15.18 \pm 0.21^{\text {cd }}$ & $0.78 \pm 0.04^{\text {cd }}$ & $78.00 \pm 0.05^{\mathrm{cd}}$ \\
TAA + ALA & $32.00 \pm 0.33^{\text {cde }}$ & $15.72 \pm 0.25^{\text {cde }}$ & $0.70 \pm 0.07^{\mathrm{d}}$ & $74.00 \pm 0.03^{\text {cde }}$ \\
TAA + L-carnitine + ALA & $28.02 \pm 0.28^{\text {cdet }}$ & $14.5 \pm 0.21^{\text {cdet }}$ & $0.85 \pm 0.05^{\text {cdt }}$ & $82.00 \pm 0.04^{\text {cdet }}$ \\
\hline
\end{tabular}

Values represent mean \pm SE, number of samples is 10 rats per group; $a ; b ; c$; $d$; e; f Significant at $p<$ 0.05 between the groups in the same rows. 
Table 4: Effect of lactulose, L-carnitine, ALA and the combined dose of L-carnitine and ALA on brain oxidant/antioxidant homeostasis in TAA-induced HE in rats

\begin{tabular}{|c|c|c|c|c|}
\hline Group & $\begin{array}{c}\text { MDA } \\
\text { (nmol/mg protein) }\end{array}$ & $\begin{array}{c}\text { NO } \\
(\mu \mathrm{mol} / \mathrm{mg} \text { protein })\end{array}$ & $\begin{array}{c}\text { GPX } \\
\text { (U/mg protein) }\end{array}$ & $\begin{array}{c}\text { SOD } \\
\text { (U/mg protein) }\end{array}$ \\
\hline Normal control (3 days) & $5.82 \pm 0.08$ & $29.93 \pm 0.36$ & $1.27 \pm 0.02$ & $3.06 \pm 0.02$ \\
\hline TAA (3 days) & $8.47 \pm 0.04^{\mathrm{a}}$ & $37.01 \pm 0.42^{\mathrm{a}}$ & $0.87 \pm 0.01^{\mathrm{a}}$ & $2.20 \pm 0.02^{\mathrm{a}}$ \\
\hline Normal control (3 months) & $5.86 \pm 0.07$ & $29.64 \pm 0.29$ & $1.26 \pm 0.02$ & $3.05 \pm 0.03$ \\
\hline TAA (3 months) & $12.90 \pm 0.11^{\mathrm{b}}$ & $55.53 \pm 0.63^{\mathrm{b}}$ & $0.56 \pm 0.02^{b}$ & $1.39 \pm 0.02^{\mathrm{b}}$ \\
\hline TAA + Lactulose & $8.00 \pm 0.26^{\mathrm{c}}$ & $38.00 \pm 0.12^{c}$ & $1.09 \pm 0.0^{C}$ & $2.79 \pm 0.04^{\mathrm{c}}$ \\
\hline TAA + L-carnitine & $8.99 \pm 0.14^{\text {cd }}$ & $42.48 \pm 0.18^{\mathrm{cd}}$ & $0.83 \pm 0.03^{\mathrm{cd}}$ & $2.00 \pm 0.02^{\mathrm{cd}}$ \\
\hline TAA + ALA & $9.99 \pm 0.15^{\text {cde }}$ & $43.86 \pm 0.14^{\mathrm{cde}}$ & $0.75 \pm 0.03^{\text {cde }}$ & $1.80 \pm 0.03^{\text {cde }}$ \\
\hline TAA + L-carnitine + ALA & $8.50 \pm 0.19^{\text {cde }}$ & $41.00 \pm 0.14^{\text {cdet }}$ & $0.90 \pm 0.03^{\mathrm{cd}}$ & $2.30 \pm 0.04^{\text {cdet }}$ \\
\hline
\end{tabular}

Table 5: Effect of lactulose, L-carnitine, ALA and the combined dose of L-carnitine and ALA on serum TNF- $\alpha$ and S100- $\beta$ levels in TAA-induced HE in rats

\begin{tabular}{lcc}
\hline Group & $\begin{array}{c}\text { TNFa } \\
(\mathbf{P g} / \mathbf{m L})\end{array}$ & $\begin{array}{c}\mathbf{S 1 0 0 \beta} \\
(\mathbf{P g} / \mathbf{m L})\end{array}$ \\
\hline Normal control (3 days) & $7.79 \pm 0.03$ & $26.74 \pm 0.16$ \\
TAA (3 days) & $16.37 \pm 0.19^{\mathrm{a}}$ & $46.06 \pm 0.53^{\mathrm{a}}$ \\
Normal control (3 months) & $7.83 \pm 0.03$ & $26.90 \pm 0.06$ \\
TAA (3 months) & $45.24 \pm 0.84^{\mathrm{b}}$ & $137.94 \pm 3.91^{\mathrm{b}}$ \\
TAA + Lactulose & $20.00 \pm 0.11^{\mathrm{c}}$ & $54.96 \pm 0.95^{\mathrm{c}}$ \\
TAA + L-carnitine & $24.99 \pm 0.11^{\text {cd }}$ & $62.98 \pm 1.74^{\text {cd }}$ \\
TAA + ALA & $26.99 \pm 0.39^{\text {cde }}$ & $65.00 \pm 0.72^{\text {cd }}$ \\
TAA + L-carnitine + ALA & $23.00 \pm 0.08^{\text {cdet }}$ & $59.00 \pm 1.39^{\text {ct }}$ \\
\hline
\end{tabular}

Values represent mean \pm SE, number of samples is 10 rats per group; $a ; b ; c ; d ; e ; f$ Significant at $p<$ 0.05 between the groups in the same rows

Serum inflammatory marker levels were significantly higher of $\mathrm{HE}$ rats $(p<0.05)$ than in those of control rats. The oral administration of Lactulose, L-carnitine and ALA $(8 \mathrm{mg} / \mathrm{kg} /$ day, $100 \mathrm{mg} / \mathrm{kg} /$ day and $100 \mathrm{mg} / \mathrm{kg} /$ day, respectively) resulted in a substantial $(p<0.05)$ reduction in TNF- $\alpha$ and S100- $\beta$ levels compared to the HE group (Table 5).

In the current investigation, Lactulose, L-carnitine and ALA treatment $(8 \mathrm{mg} / \mathrm{kg} /$ day, $100 \mathrm{mg} / \mathrm{kg} / \mathrm{day} \quad$ and $100 \mathrm{mg} / \mathrm{kg} /$ day, respectively) demonstrated significant protective effect in all studied parameters whereas the antioxidant activity of the L-carnitine in combination with ALA was superior.

\section{DISCUSSION}

HE occurs in both acute and chronic liver disease and there is a good correlation between blood ammonia and severity of $\mathrm{HE}$. Hyperammonemia plays a major role in the development of brain edema and in evoking changes in cerebral blood flow (CBF) [13]. There are several drugs and clinical trials that could benefit patients with $\mathrm{HE}$ and most of them tend to reduce the production and absorption of ammonia from the colon, with the hypothesis that the colon is the primary organ that generates ammonia [14]. Recently, it was recorded that lactulose is the most commonly utilized nonabsorbable disaccharide for prophylaxis of $\mathrm{HE}$ [15].

In the current work, marked amelioration has been detected in the all studied parameters after treatment of TAA-intoxicated group with lactulose for 3 months. Marked improvement in liver functions as indicated through detectable decrease in serum ALT, AST and bilirubin levels with significant elevation in TP and ALB levels. This effect may be attributable to conversion of ammonia to poorly absorbable ammonium ion and decrease in ammonia production by bacteria. Lactulose showed significant reduction in serum, liver and brain ammonia levels. The present results are consistent with the previous study reporting that lactulose could significantly lower the level of hyperammonemia [16].

In the present investigation, lactulose can significantly restore the balance between oxidants and antioxidant of liver and brain in 
TAA-intoxicated group compared with the untreated ones. This finding is represented by the reduction of pro-oxidants (MDA and NO) with activation of the antioxidant enzymes (GPX and SOD). These results are due to reduction of oxidative stress in hepatocytes leading to increased hepatic clearance of ammonia in $\mathrm{HE}$ rat model. Lactulose and molecular hydrogen has been found to activate the expression of Nrf2 and they could indirectly activate the endogenous antioxidant system [17].

The anti-inflammatory effect of lactulose has been demonstrated in the current study through down-regulation of serum TNF- $\alpha$ and S100 $\beta$ levels. The current data is consistent with Zhai et al [18] who showed the ability of Lactulose to perform hepatoprotective and neuroprotective effects due to its free radical- scavenging.

The present data revealed that oral administration of L-carnitine to TAA-intoxicated rats significantly reduced serum levels of ALT, AST and bilirubin level while significantly increased serum TP and ALP levels. These results could be attributed to the direct antioxidant action of L-carnitine with hepatoprotective effect that enable it to protect plasma membranes from the attacking of free radicals and prevent their damage. Furthermore, L-carnitine exerts protective effects against cerebral energy distortions and neuronal dysfunction in HE suggesting that L-carnitine acts as a potential therapeutic agent in metabolic encephalopathy such as ammonia-precipitated HE [19].

The concomitant reduction in serum, liver and brain ammonia concentrations as a consequence of L-carnitine supplementation as shown in the present study confirm the effect of L-carnitine on ammonia clearance that prevent acute ammonia toxicity and reduce its effects on the brain with significant improvement in the cellular redox state as well as mitochondrial energy metabolism.

In the present investigation, L-carnitine could significantly maintain balance between prooxidants and antioxidants in the liver and brain of TAA- intoxicated rats. Also, L-carnitine exhibits antioxidant effect by reducing metabolic stress and showed significant suppression in MDA and NO production associated with a significant elevation in GPX and SOD activities in liver and brain tissues [20]. The anti-inflammatory activity of $\mathrm{L}$-carnitine has been demonstrated in the current study through decreasing serum TNF-a and S100- $\beta$ levels in TAA+ L-carnitine group suggesting that carnitine played a major role in controlling the level of circulating cytokines and to the suppression of neutrophil infiltration [21].

Several studies have focused on the antioxidant properties of ALA. ALA is effective in both prevention and treatment of oxidative stress in a number of models and clinical conditions including ischemia-reperfusion injury, diabetes, HIV infection and neurodegenerative diseases [22]. In light of the obtained data, oral administration of ALA in HE rats inhibited the development of liver cirrhosis through significant attenuation of serum ALT, AST activities and bilirubin level with significant modulation of TP and ALP levels. Moreover, the beneficial effects of ALA treatment on HE rats have been indicated through marked correction of serum, liver and brain ammonia levels. These results suggest that ALA restored the deficiency of glutamine synthesize flow into the cells with consequent increment in glutamine production and correction of ammonia utilization [23]. In addition AA administration significantly reduced MDA and SOD levels and significantly improved the activities of GPX and SOD in liver and brain tissues. The protective effect of ALA is derived from its ability to counteract ROS generation and exhibited beneficial role in the treatment of chronic liver diseases [24]. ALA treatment of HE - induced rats significantly decremented serum TNF- $\alpha$ and S100- $\beta$ levels. Concentrations, consistent with its anti- inflammatory potential.

In the present study, L-carnitine in combination with ALA was effective in the treatment of chemically induced liver fibrosis in rats. All parameters were significantly $(p<0.05)$ ameliorated. Their antioxidant mechanisms involve the inhibition of oxidative stress, inflammation, level of hyperammonemia as well as metabolic disturbances in TAA - induced liver and brain Tissues. Therefore, their combination may be used as a potential hepatoprotective, neuroprotective and anti-fibrotic agent.

\section{CONCLUSION}

The findings of this study indicate that the combination of L-carnitine and ALA exerts significant antioxidant, anti-inflammatory and anti-fibrotic activities, and thus possesses hepatoprotective and neuroprotective effect. Therefore, the combination product has the potentials to be developed for the management of liver cirrhosis. 


\section{DECLARATIONS}

\section{Acknowledgement}

The authors gratefully appreciate the support from Faculty of Women for Arts, Science and Education, Ain Shams University, Cairo, Egypt.

\section{Conflict of Interest}

No conflict of interest associated with this work.

\section{Contribution of Authors}

The authors declare that this work was done by the authors named in this article and all liabilities pertaining to claims relating to the content of this article will be borne by them.

\section{Open Access}

This is an Open Access article that uses a funding model which does not charge readers or their institutions for access and distributed under the terms of the Creative Commons Attribution License (http://creativecommons.org/licenses/by/ 4.0) and the Budapest Open Access Initiative (http://www.budapestopenaccessinitiative.org/rea d), which permit unrestricted use, distribution, and reproduction in any medium, provided the original work is properly credited.

\section{REFERENCES}

1. Patidar KR, Bajaj JS. Covert and overt hepatic encephalopathy: diagnosis and management. Clin Gastroenterol Hepatol 2015; 13: 2048-2061.

2. Algandaby MM. Antifibrotic effects of crocin on thioacetamide-induced liver fibrosis in mice. Saud J Biol Sci 2016; (In Press).

3. Prasad S, Dhiman RK, Duseja A, Chawla YK, Sharma A, Agarwal R. Lactulose improves cognitive functions and health-related quality of life in patients with cirrhosis who have minimal hepatic encephalopathy. Hepatol 2007; 45: 549-559.

4. Malaguarnera M, Gargante MP, Cristaldi E, Vacante M, Risino C, Cammalleri L, Pennisi G, and Rampello $L$. Acetyl L-carnitine treatment in minimal hepatic encephalopathy. Dig Dis Sci 2008; 53: 3018-3025.

5. Hassan A, Tsuda Y, Asai A, Yokohama K, Nakamura K, Tetsuya Sujishi T, Ohama $H$, Tsuchimoto $Y$, Fukunishi S, Abdelaal UM, Arafa UA, Ali T, Hassan AT, Ali M, Kassem AM, Higuchi K. Effects of Oral L-Carnitine on Liver Functions after Transarterial Chemoembolization in Intermediate-Stage HCC Patients. Media Inflamm 2015; 2015: 1-10.

6. Sakai $Y$, Nishikawa $H$, Enomoto $H$, Yoh $K$, Iwata $Y$, Hasegawa K, Nakano C, Kishino K, Shimono Y, Takata
R, Nishimura T, Aizawa N, Ikeda N, Takashima $T$, Ishii A, lijima $H$, Nishiguchi S. Effect of L-Carnitine in Patients With Liver Cirrhosis on Energy Metabolism Using Indirect Calorimetry: A Pilot Study. J Clin Med Res 2016; 8:863-869.

7. Shinto L, Quinn J, Montine T Dodge HH, Woodward W, Baldauf-Wagner S. A randomized placebo-controlled pilot trial of omega-3 fatty acids and alpha lipoic acid in Alzheimer's disease. J Alzheimer's dise 2014; 38: 111120.

8. Abdou RH, Abdel-Daim MM. Alpha-lipoic acid improves acute deltamethrin-induced toxicity in rats. Can J Physio Pharmacol. 2014; 92: 773-779.

9. Abdel-Daim MM, Taha R, Ghazy EW, El-Sayed YS. Synergistic ameliorative effects of sesame oil and alphalipoic acid against subacute diazinon toxicity in rats: hematological, biochemical, and antioxidant studies. Can J Physio Pharmacol 2016; 94: 81-88.

10. National Research Council (NRC). Guide for the Care and Use of Laboratory Animals: 8th Ed, 2011. [cited $2013 \mathrm{Apr} 3$ 3. Available from: https://grants.nih.gov/ grants/olaw/Guide-for-the-Careand- use-of-laboratoryanimals.pdf.

11. Lin CC, Hus YF, Lin TC, Hsu FL, Hus HY. Antioxidant and hepato protective activity of punicalagin-induced liver damage in rats. J Pharmacol 1998; 50: 789-794.

12. Tsakiris S. Effects of L-phenylalanine on acetylcholinesterase and $\mathrm{Na}+, \mathrm{K}_{+}-$ATPase activities in adult and aged rat brain. Mech. Ageing Dev 2001; 122 : 491-501.

13. Bajaj JS. Review article: potential mechanisms of action of rifaximin in the management of hepatic encephalopathy and other complications of cirrhosis. Aliment Pharmacol Ther 2016; 43:11-26.

14. Mousa N, Abdel-Razik A, Zaher A, Hamed M, Shiha G, Effat N, Elbaz S, Elhelaly R, Hafez M, El-Wakeel $N$, Eldars $W$. The role of antioxidants and zinc in minimal hepatic encephalopathy: a randomized trial. Therap Adv Gastroenterol 2016; 9: 684-691.

15. Maharshi S, Sharma $B$, Srivastava $S$, Jindal $A$. Randomised controlled trial of lactulose versus rifaximin for prophylaxis of hepatic encephalopathy in patients with acute variceal bleed. Gut J 2015; 64: 1341-1342.

16. Sidhu S, Goyal O, Parker R, Kishore H, Sood $A$. Rifaximin vs. lactulose in treatment of minimal hepatic encephalopathy. Liver Int 2016; 36: 378-385.

17. Chen $X$, Zuo $Q$, Hai $Y$, Sun XJ. Lactulose: an indirect antioxidant ameliorating inflammatory bowel disease by increasing hydrogen production. Med. Hypotheses 2011; 76: 325-327.

18. Zhai $X$, Chen $X$, Shi J, Shi D, Ye Z, Liu W, Li M, Wang $Q$, Kang $Z$, Bi $H$, Sun $X$. Lactulose ameliorates cerebral ischaemia-reperfusion injury in rats by inducing hydrogen by activating Nrf2 expression. Free rad Biol Med 2013; 65: 731-741.

19. Demiroren K, Dogan Y, Kocamaz H, Hanifi I, Ilhan S, Ustundag $B$, Halil I. Protective effects of L-carnitine, $\mathrm{N}$ acetylcysteine and genistein in an experimental model

Trop J Pharm Res, September 2017; 16(9): 2167 
of liver fibrosis. Clin Res Hepatol. Gastroenterol 2013; 10: 1-10.

20. Canbolat EP, Sağsöz N, Noyan V, Yücel $A$, Kısa Ü. Effects of L-carnitine on oxidative stress parameters in oophorectomized rats. Alexandria J Medi. Available 2016; (In Press)

21. Hassan A, Tsuda Y, Asai A, Yokohama K, Nakamura K, Tetsuya Sujishi T, Ohama H, TsuchimotoY, Fukunishi S, Abdelaal UM., Arafa UA, Ali T., Hassan AT, Ali M, Kassem AM, Higuchi K. Effects of Oral L-Carnitine on Liver Functions after Transarterial Chemoembolization in Intermediate-Stage HCC Patients. Media Inflam2015; 2015: 1-10.
22. Abdou RH, Abdel-Daim MM. Alpha-lipoic acid improves acute deltamethrin-induced toxicity in rats. Can J Physio Pharmacol. 2014; 92: 773-779.

23. Al-Mehdar AA, El-Denshary ES, Abdel-Wahhab M.A. Alpha lipoic acid and alpha-tocopherol counteract the oxidative stress and liver damage in rats sub-chronically treated with khat (catha edulis) extract. Global $J$ Pharmacol 2012; 6:94-105.

24. Najafi R, Sharifi AM, Hosseini A. Protective effects of alpha lipoic acid on high glucose-induced neurotoxicity in PC12 cells. Meta Br Dis 2015; 30: 731-738. 